\title{
Increase of Competitiveness of Tourist Industry Companies on the Basis of Marketing Approaches
}

\author{
Lyudmila I. Chernikova
}

Doctor of Sciences, Professor of the Chair "Corporate Finances" of Financial University with the Government of the RF; Email: tariff2004@mail.ru

Guzel R. Faizova

Ph.D., leading economist of "Scientific enterprise "Proekt-Avtomatika" LLC Email:guzel_faizova@mail.ru

\section{Elena N. Egorova}

Ph.D., Docent of the Chair "Accounting and finances" of Moscow Institute of State and Corporate Management; Email: egelni@yandex.ru

Anna A. Silaeva

Ph.D., Docent of the Chair "Economics and Management" of Russian State University of Tourism and Service ; Email:silaeva-aa@bk.ru

Doi:10.5901/mjss.2015.v6n6s4p99

\section{Abstract}

Under the modern conditions of quick development of tourism in the world, which sets strict requirements to the level of work of tourist companies, there is an urgent need for systemic study of general and specific attributes of tourist business, its organization, regularities of development and management, and its intersectoral and infrastructural interconnections. The article studies peculiarities of development of tourist market in Russia and factors of development of tourism under the conditions of economic instability, determines top-priority directions of state's support for tourist industry, distinguishes main attributes of tourist services which should be taken into account during marketing research, and determines main stages of marketing research. It is determined that under the conditions of economic and political instability, the necessity for reorientation of the flow of international outbound Russian tourism at the development of internal tourism is obvious, and development of tourist industry requires a complex of measures that consists in formation of effective system of marketing, thus leading to the necessity for satisfaction of needs of foreign and internal tourists in the region of stay. The main purpose of this article is to determine factors of development of tourism under the conditions of economic instability and develop methodological instrumentarium for increase of competitiveness of tourist industry enterprises under the modern conditions. The authors use the data received as a result of research, conducted with the use of methods of statistical and graphical analysis, which allowed reflecting specifics of tourist market in Russia and of strategic segmenting. The result of implementation of these measures of tourism development and use of marketing instrumentarium will be the creation of modern and technically equipped tourist industry, capable of satisfying needs of Russian and foreign citizens.

Keywords: tourism, tourist flow, tourist infrastructure, marketing in tourism, tourist industry

\section{Introduction}

Development of the market of international services is one of the manifestations of globalization. Under the influence of expansion of the processes of integration and globalization, which take place in the modern global economy, this tendency became peculiar for most countries of the world. As practice shows, service sphere is one of the most important and rapidly increasing components of the global economy. Thus, in developed countries of the world, the share of service sphere in the structure of GDP exceeds $70 \%$ with employment of more than $60 \%$ of workforce. An important sector in the structure of international service market is tourism, which, due to quick rates of growth in the first decade of the $21^{\text {st }}$ century (despite the global crisis, range of natural cataclysms, and political conflicts) became the first as to economic 
effectiveness, leaving behind such spheres as car industry and oil extraction. Still, tourism is not only a powerful tool of economic development. It can be a powerful factor for creation of image of certain territory, propaganda of its history, and achievement of the future (Shpileva I.N., 2015).

The Russian Federation holds a form position in the international tourism market; in 2012, Russia ranked among the top-10 countries as to the number of tourist visits, showing a serious two-digit rate of growth of this indicator (13.4\%) and ranked $5^{\text {th }}$ as to tourists' expenses. Around $4.8 \%$ of the global tourist flow accounts for Russia in 2012. At that, revenues from tourist also grew over the three years, but this growth was insignificant (1.2\%). Under these conditions, special actuality belongs to the study of issues of the increase of competitiveness of companies of tourist industry on the basis of marketing approaches.

\section{Main Part}

\subsection{Top-priority directions of state's support for tourist industry}

Tourism is viewed as a source of financial income of budgets of all levels, means for increase of employment and population's living standards, means for improvement of citizens' health, basis for development of socio-cultural environment and education of patriotic feelings of the youth, and powerful tool for enlightenment and formation of moral platform for development of civil society.

In 2002-2005, Russia implemented the Concept for tourism development, approved by the decree of the Government of the Russian Federation dated July 11, 2002, No. 954-r; then, in 2008, the Strategy for development of tourism in the Russian federation until 2015 and the plan of measures for its implementation was approves.

On May 31, 2014, the Decree of the Government of the Russian Federation approved the Strategy of development of tourism in the Russian Federation until 2020.

The Strategy is inseparable part of the Concept of long-term socio-economic development of the Russian Federation until 2020, and is fully associated with the tasks of the State program of the Russian Federation "Development of culture and tourism" for 2013-2020. Also, the developed Strategy continues the planned documents, realized in the sphere of tourism in previous years, takes into account the global tendencies and modern state of the sphere in view of current and perspective tasks of state management in the sphere of culture, patriotic education of the youth, social provision of population, physical culture and sports, education, support for employment, and preservation of natural and cultural \& historical resources of the country. According to the provisions of this Strategy, a Plan of measures for its implementation until 2020 was developed, which is an inseparable part of the Strategy.

An important stage of the development of tourist sector is 2011 federal target program (hereinafter referred to as FTP) "Development of internal and inbound tourism in the Russian Federation (2011-2018)", the principles of which are based on partnership of the state and private sector.

The federal target program was developed for the purpose of increasing the competitiveness of tourist market of the Russian Federation, which satisfies the needs of the Russian and foreign citizens in high-quality tourist services.

The main tasks of the FTP are:

- development of tourist and recreational complex of the Russian Federation;

- increase of the quality of tourist services;

- promotion of tourist product of the Russian Federation in the global and internal tourist markets.

The FTP supposes development of state-private partnership in tourism, i.e., active and mutually profitable relations between bodies of state management at the federal, regional, and local levels and companies and public organizations of tourist sphere. At that, main role of the state will consist in financing and creation of engineering infrastructure and creation of favorable investment climate of territories. Groups of cooperating companies, public organizations, and public authorities bodies, united by territorial proximity and participating in servicing of tourist flows, will unite into tourist and recreational clusters in view of key regional resources.

The program consists of two stages: first stage - 2011-2014; second stage - 2015-2018.

The expected final results of implementation of the Program are:

- creation in various subjects of the Russian Federation of the network of competitive tourist \& recreational and car tourist clusters, which will become points of connections, activating the development of small and medium business around them (growth of investments into the main capital of accommodation means (hotels, places of temporary growth) by 1.9 times as compared to 2010);

- satisfaction of needs of various categories of citizens of the Russian Federation for active recreation, 
improvement of health, cultural values inclusion (growth of the number of Russians, accommodated in collective means of accommodation, by 1.5 times, as compared to 2010);

- increase of the level of employment of population be means of creation of additional jobs in the sphere of tourism (increase of the number of employed in collective means of accommodation by $41 \%$ and of the employed in tourist companies by $51 \%$, as compared to basic level of 2010);

- increase of the budget revenues of the budget system of the Russian Federation due to the increase of the volume of provision of services in the sphere (increase of the volume of paid tourist services, provided to population, by 4.7 times, and volume of paid services of hotels and similar means of accommodation by 4.3 times as compared to 2010);

- growth of GDP and improvement of current account balance of the country (growth of the number of foreign citizens accommodated in collective means of accommodation by 6.4 times as compared to 2010) (Egorova E.N., 2013).

The cause for such successful development of the sphere in the world is socio-economic effect, received as a result of development of internal and inbound tourism (hereinafter referred to as - IIT) (Kufireva I.G., 2011):

- IIT creates jobs in the sector of tourism and related spheres (each inbound tourist creates 8-10 jobs);

- stimulates the development of internal sub-spheres: hotel \& tourist and sanatorium-resort complex, transport and restaurant business, excursion and informational services, tourist \& entertainment, sports \& recreational, and business centers;

- stimulates the inflow of foreign currency into the country (region);

- stimulates investments into local tourist industry, stipulating the increase of taxable basis and income of budgets;

- stimulates modernization of local infrastructures of transport, communication, and other basic systems;

- stipulates preservation and recovery of historical \& cultural and natural inheritance of the country (region);

- stimulates resurrection and development of traditional folk industries and crafts, manufacture of souvenir production;

- stipulates effective eco-oriented use of lands that do not have agricultural meaning, which allows preserving natural flora on large territories, and shows large importance of natural and cultural resources for economic and social well-being of the society;

- $\quad$ forms the prestige of the region and country on the whole.

\subsection{Specifics of tourist market in Russia}

Fig. 1 shows the dynamics of outbound and inbound tourists in Russia for 2006-2014. In 2014, around 17.6 million people went abroad from Russia as tourists, while 2.6 million people visited Russia. In 2009-2013, there was a growth of inbound tourists and Russians who travelled abroad. The recent year showed the reduction of these indicators by $3 \%$ and $4 \%$, correspondingly - which was caused by sanctions from foreign countries and ruble depreciation, thus weakening the Russian tourist industry by the end of the year.

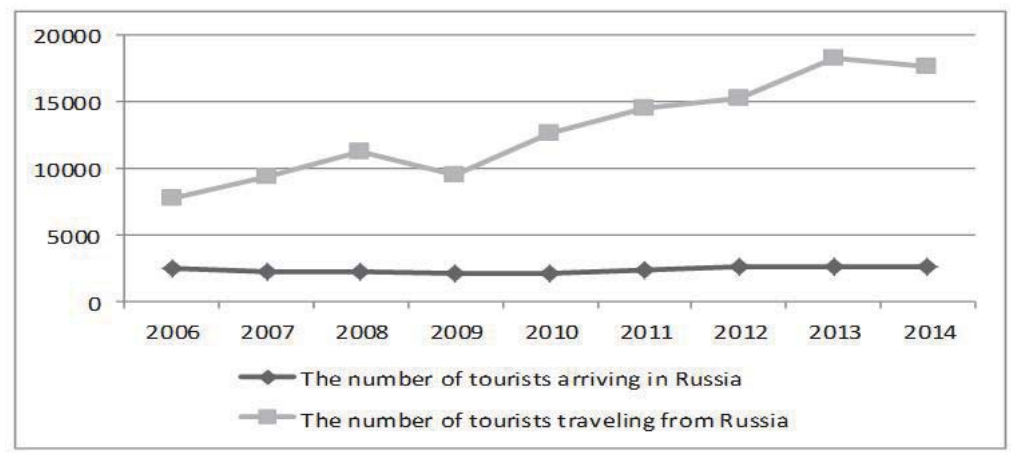

Figure 1. Number of inbound and outbound tourists in Russia, thousand people. 
In Russia, outbound tourism develops much faster than inbound one (Fig. 2). Inbound tourist flow grew constantly in 2000-2008 with significant reduction in 2009, which was explained by the global financial crisis. However, in 2010, the growth rate constituted $132 \%$, which is higher than 2008 level by $11 \%$. The dynamics of inbound tourism is not stable, its indicators grow and reduce. Due to the global financial crisis, the number of foreign tourists that visited Russia reduced in 2009, as compared with previous years. Over 2010-2013, there was observed a positive tendency of inbound tourist flow, though growth rate was not high - 102\% in 2010, 109\% in 2011, 110\% in 2012, and 104\% in 2013.

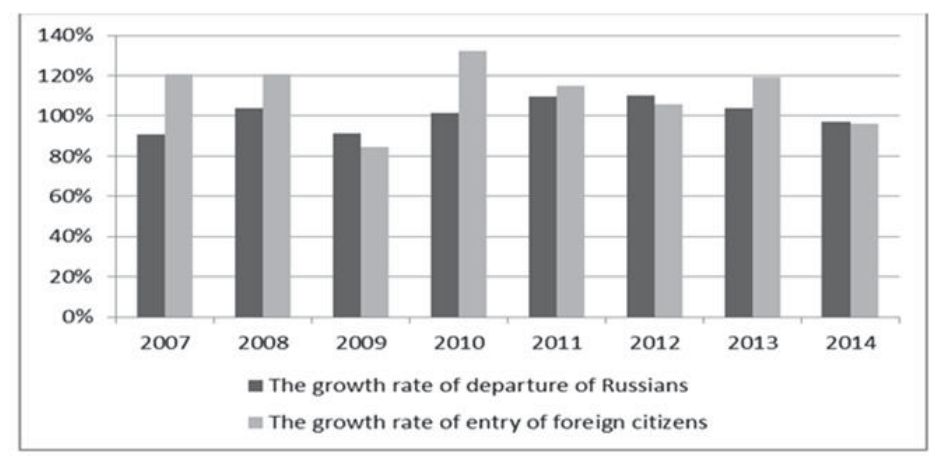

Figure 2. Number of inbound and outbound tourists in Russia, thousand people.

Excess of outbound international tourism over the inbound one has been observed from 1996, but back then the difference was lower than now. Rapid growth began in 2009. Thus, in 1996, the import of tourist services exceeded the export by USD 2.9 million, in 2000 - by USD 5.4 million, in 2005 - by 11.4 million, in 2010 - by 17.9 million, and, finally, in 2013, the difference constituted USD 41.5 million. This data shows that tourism in Russia in not a source of currency revenues, but a channel of outflow of currency from the country. In the global market, this tendency is also very vivid - at present, only $5 \%$ of the global import of tourism and $1 \%$ of export account for Russia.

According to the State Statistics Service, the number of Russians who travel abroad reduced in 2014 by $15 \%$ mainly, due to reduction of official and private trips - thus constituting 45,882,000 (See Fig. 3). The largest share in the structure of trips belongs to private trips $-53 \%$, and tourist and official trips account for $38 \%$ and $2 \%$, correspondingly. It should be noted that the number of tourist trips slightly reduced in 2014 (-4\%). This fact could be caused by the growth of frequency of trips and reduction of demand for tourist trips abroad.

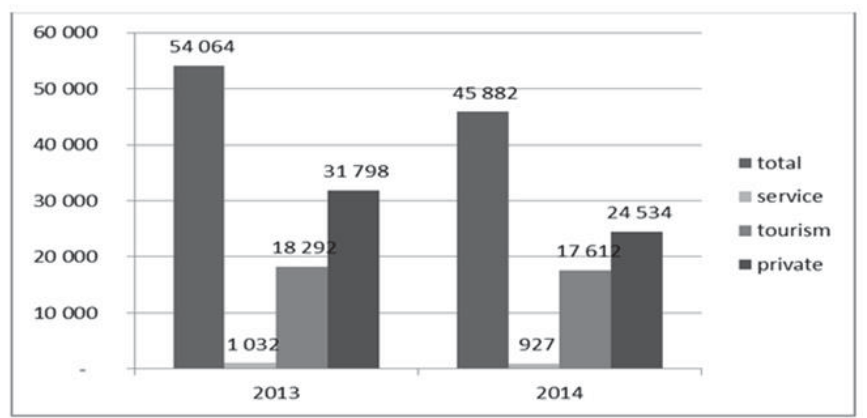

Figure 3. Number of trips abroad by Russians, thousand.

Among the countries, which citizens arrive in the RF, the leading positions belong to China - 409,817, Germany 349,481, the USA - 162,102 (see Fig.4). 


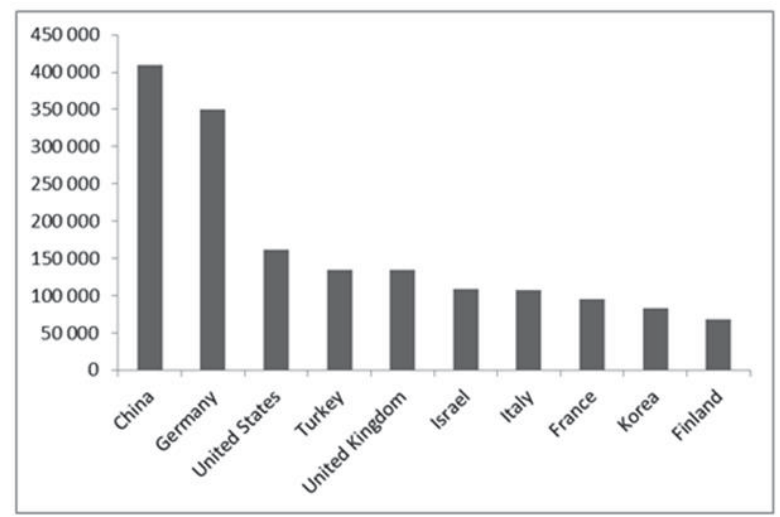

Figure 4. Top-10 of foreign tourists' entry in the RF in 2014 (purpose-tourism)

Internal tourism has a positive tendency of growth. As compared to previous years, the number of people wishing to travel in Russia grew. Despite the existing problems in Russia, the tourist sphere develops and is reformed.

According to the State Statistics Service, the number of foreign citizens who arrived to Russia in 2014 constituted $32,421,000$, which is by $5 \%$ more than in previous year (see Fig. 5) The largest shares in the structure of trips belong to private trips $-65 \%$ and official and tourist trips $-19 \%$ and $8 \%$, correspondingly. It should be noted that in 2014 , there was reduction of number of tourist trips by $3 \%$. The countries, the citizens of which arrived in Russia the most, are Poland, Finland, and Germany (see Table 1).

Table 1. Countries leading in arrivals in the RF

\begin{tabular}{|c|c|c|}
\hline & Citizenship & Number of trips \\
\hline 1. & Poland & $1,823,143$ \\
\hline 2. & Finland & $1,446,169$ \\
\hline 3. & Germany & 635,153 \\
\hline 4. & Lithuania & 487,206 \\
\hline 5. & Latvia & 374,701 \\
\hline 6. & Estonia & 363,942 \\
\hline 7. & Great Britain & 228,346 \\
\hline 8. & Italy & 219,976 \\
\hline 9. & France & 219,210 \\
\hline 10. & Spain & 100,206 \\
\hline
\end{tabular}

The reduction of foreign tourist flow in Russia is caused by: unfavorable political situation in the world; growing prices for tourist package due to growing prices for air and railway tickets; insufficient quality of services provided to foreign tourists; preservation of negative stereotypes regarding Russia, supported by some representatives of foreign mass media, etc. (Istomina T.S., 2015). 


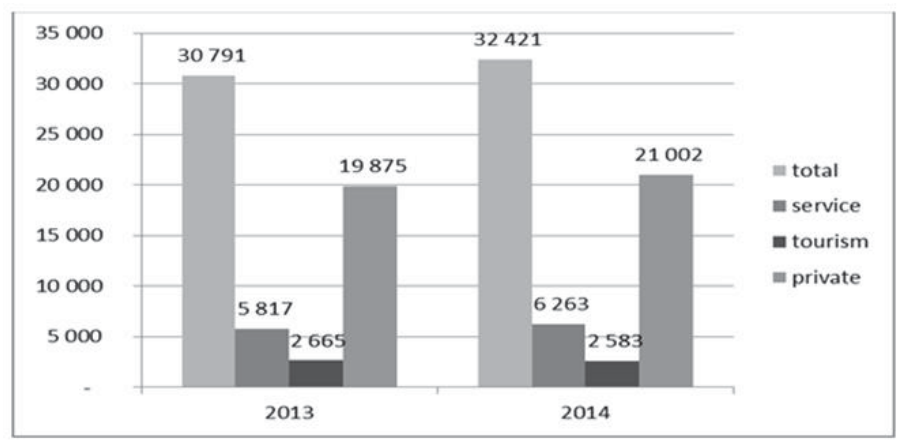

Figure 5. Number of trips of foreign citizens to Russia, thousand.

Figure 6 shows expected values of one of the target indicators of implementation of the Strategy of development of tourism in the Russian Federation until 2020 - arrival of foreign citizens to Russia.

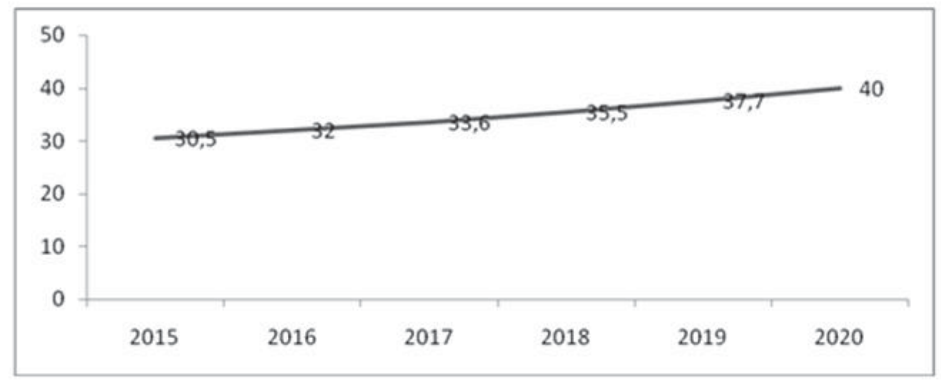

Figure 6. Expected value of targeted indicator of implementation of the Strategy - arrival of foreign citizens to Russia, million trips.

The expected values of development of internal tourism in the RF show sustainable growth of demand for recreation in Russia. These changes of the vector of consumer demand are caused not only by economic and political issues. There are gradual changes in consumer behavior. At present, most Russians pay attention to regions of their own country. At the same time, the average length of a tour in Russia in 2014 constituted 3.5 days, and average cost of accommodation constituted RUB 3,900 per day, which is by $15 \%$ less than abroad. More attractive prices for accommodation together with reduced tariffs for flights and low cost companies make the internal tourist product more attractive for Russians. At that, the crisis of the Russian tourist market, unfortunately, continues, and it is necessary to comprehend its causes and consequences. Making an attempt to compare the crises of 2008 and 2014, we cannot but note their similarity and, at the same time, certain differences (Dzhandzhugazova E.A., 2015).

\subsection{Factors of development of tourism under the conditions of economic instability}

Large tour operators began to work in the internal market in 2014. At that time, CoralTravel and Biblio Globus announced the increase of sales of tours to the Russian resorts. This strategy proved right in winter 2015, when the ruble depreciation and reduction of demand for foreign resorts led to $30 \%$ increase of sales in the internal market.

Under the conditions of economic and political instability, the necessity for reorientation of the flow of international outbound Russian tourism at the development of internal tourism is obvious, thus leading to the necessity for satisfaction of needs of foreign and internal tourists in the region of their stay.

It is obvious that work on the strategy and plans of development of tourism in the Russian Federation needs to take into account positive and negative factors which can be rather influential. 
Positive factors include:

- despite the reduction of foreign tourists' trips to the Russian Federation in 2014, the analysts expect the growth of indicators of tourist arrivals;

- volume of arrivals remain significant as compared to previous years;

- the Russian Federation is in top-10 leaders as to receiving foreign guests;

- rates of growth of indicators of inbound tourism for the Central and Eastern Europe sub-region, which includes the Russian Federation, are expected for 2010-2020 to be higher (3.7\% per year) than in Europe on the whole (2.7\%); also, the forecast shows that tourist arrivals into developing countries will grow with double rates as compared to the developed countries (4.4\% against 2.2\%) (Arakcheeva Z.V.,2015);

- the Russian Federation is capable of satisfying the growing demand of people for cultural and educational interest, taking into consideration the significance of cultural inheritance and development of natural tourism of Russia. All establishments of culture show positive dynamics. There are $74,361,967$ museums in the Russian Federation. The number of museum visits, which reduced drastically in 2009 , grows annually with moderate rates by $4 \%$ a year;

- growing demand of the Russians for internal tourist and cultural tourist products.

It should be noted that in spite of the fact that the infrastructure of the internal tourist business does not correspond to the global level, it developed a lot over the recent years, which is proved by the growth of the number of collective means of accommodation, increase of the length of hard-top roads, and investments into this sphere.

Negative factors include:

- unreadiness of the Russian Federation to effectively use favorable tendency of the increase of arrivals of foreign citizens and receipt of corresponding income;

- Russian tourists prefer foreign resorts with high level of service;

- insufficiently comfortable informational environment - this relates to lack of tourist navigation signs, lack of informational resources in Russian tourist programs, ineffective schedule of work of many tourist objects (cleaning days, short working hours, non-conformity with dominating rhythm of arrival of foreign citizens with tourist purposes as to days of the week), and impossibility of preliminary reservation and purchase of museum tickets via the Internet;

- lack of centralized and unified informational resources tours search in Russia;

- level of security provision of foreign tourists during their stay in the Russian Federation does not correspond to international standards;

- insufficiently developed tourist infrastructure in most regions of the country, small number of hotel means of accommodation of economy and medium pricing class with modern level of comfort;

- low level of development of transport infrastructure (low quality of roads and level of roadside service, unsatisfactory state of airports and railway stations, etc.);

- deficit and high level of wear of vehicles used for tourist transportation (modern tourist buses, cruise ships, airplanes, and other vehicles);

- ages and ineffectively used resource basis in the sphere of sanatorium-resort, recreational, and medical tourism (resorts and holiday centers), lack of establishments of children and youth tourism;

- lack of approach roads and equipped grounds for amateur nature-oriented tourism;

- bad ecological state and littered coastal areas of reservoirs and natural territories, used by amateur tourists;

- bad economic conditions for attraction of investments into tourist infrastructure, lack of final investment platforms and typical investment projects, large number of administrative barriers;

- insufficient business activity of population in the sphere of tourism;

- tendency for monopolization of the market of tourist services from large federal players of tourist business;

- negative experience of a series of bankruptcies of large tour operators and high consumer risks due to compensation nature of recovery of losses of buyers in case of financial inability or misbehavior of tour operators;

- high cost of the Russian tourist product - primarily, transport service - which significantly reduces the competitiveness of inbound and outbound tourism as to the price;

- high level of seasonal cyclicity of demand for most of tourist programs, length of "low season" in regions of traditional beach tourism, and high average constant expenses of tourist companies;

- incompatible volumes of hotel basis of traditional Russian beach resorts, allowable recreational load, and 
capacity of beaches and other objects of tourist infrastructure;

- weak practical orientation in training of tourist business professionals;

- conservatism of approaches to formation of tourist programs, low diversity of assortment of tours in Russia which are capable of satisfying the dynamic and perfectionist demand of modern consumer;

- lack of client-oriented policy of management of culture establishments, requirement for modernization of their services;

- imperfect order of issue of Russian visas to tourists from the countries that are safe as to migration issues;

- insufficient promotion of tourist product of Russia in the internal market;

- low knowledge of the Russians regarding tourist possibilities of Russia, fragmentation of informational resources in the sphere of tourism, and lack of comprehensive system of informational support for inbound and outbound tourism;

- tough level of competition in the international tourist market influences significantly the reduction of profitability of the Russian tourist industry and non-competitiveness of the Russian internal product. At that, Russian tourists' demand for internal recreation grows, which motivates tour operators to struggle for the share of the internal market which is traditionally popular among independent travellers. The tour operators' data shows that certain tours are sold under cost - for example, a trip to Crimea for one week with flight, accommodation, and food costs at least RUB 6,000, while a trip to Krasnodar Krai resorts costs at least RUB 10,000. The prices set by the operators are under cost. The current dumping is caused by massive entry of large players into the internal market, in which $70 \%$ traditionally belonged to independent tourism.

\section{Methodological Instrumentarium for the Increase of Competitiveness of Companies of Tourist Industry}

The Unified Federal Register of Tour Operators included 4,465 tour operators as of beginning of 2012. However, only 642 companies, or $14.4 \%$ of the total number of operators, worked in the sphere of inbound tourism.

According to the Federal Tourism Agency, the Federal Register of Tour Operators reduced by 155 companies during 2014: 66 of them had worked in the sphere of internal tourism, 38 - received foreigners in Russia, and 61 were involved in outbound tourism. As of now, there are 1,380 tourism companies in the Unified Federal Register of Tour Operators. This year, 21 tour operators left the market - most of them had worked in the sphere of outbound tourism (Istomina T.S., Samoilenko A.A., 2015).

The main goal of activities of operators is development of tourist services and tourist product according to requirements to the quality set by consumers and according to demand for these services. Marketing is a very effective tool for the increase of tourism services quality and, consequently, their competitiveness in the market.

Tourism does not differ much from other forms of economic activities. That's why all significant provision of modern marketing can be applied in tourism.

At the same time, tourism has specifics which distinguish it not only from the trade in products but from other forms of trade in services. It is the trade in services and goods (according to specialists, the share of services in tourism constitutes $75 \%$, the share of goods - 25\%) and special character of consumption of tourist services and goods in the place of their production and in certain situation (Durovich A.P., 2008).

In traditional production, which has a specific result of labor, the notion of marketing has a more specific content. In tourism, the result of activities is brought down to tourist product. Marketing in tourism is a system of constant coordination of offered services with services that are in demand in the market and which could be offered by travel company for gaining profit and more effectively than it is done by their rivals. The idea of marketing supposes that offers of tourist services be oriented at consumer and there be constant coordination of capabilities of a company with market's requirements.

The United Nations World Tourism Organizations distinguishes three main functions of marketing in tourism:

- establishment of contacts with clients;

- development;

- control.

Establishment of contacts with clients aims at convincing them that the offered option for accommodation and corresponding services, places of interest, and expected profits conform to what clients want to have.

Development supposes design of novelties which will provide new possibilities for sale. In their turn, such novelties should correspond to requirements and preferences of potential clients.

Control supposes analysis of the results of activities for promotion of services in the market and verification of them 
reflecting the full and successful use of possibilities that exist in the sphere of tourism.

However, marketing expands its functions, focusing mainly on relations with consumers, quality of tourist product, and its competitiveness in the market of tourist services. Long-term interrelations with clients are much cheaper than marketing expenses, necessary for strengthening of consumer's interest to services of a new client's company.

Thus, at present, the main functions of marketing in tourism include:

— accounting of market demand;

— determination of optimal assortment of offered tourist products;

- effective decisions;

- development of sale policy of tourism companies.

Generalizing the above, it is possible to make the following conclusions: main function of marketing consists in targeted influence on the formation of recreational needs, demand, commercial prices, market segmentation, development of assortment of tourist services, and their competitiveness.

While viewing the tourist industry, one cannot but note that population's ideas of the best forms of recreation change - and the popularity of prestigious recreation places does so as well. The number of business travellers grows and their opinions and wishes should be taken into account, as business tourism develops very quickly. That's why, any travel company should track all changes that happen in the market of tourist services and be quick enough to react to each of it: lagging behind the rivals may lead not only to the loss of certain share of clients but to aggravation of general image of the company, i.e., to the loss of significant part of potential and regular customers and, consequently, to reduction of competitiveness of enterprise on the whole.

Marketing research is necessary for successful work of any company. It is conducted by large companies which can afford to keep a special department. There could be one or dozens of employees in such company. The department employees include designers of research plans and statistics, sociologists, psychologists, and specialist in modeling. Small companies can apply for planning or conduct of such research to special organization or cooperate for such work.

The main tasks of marketing research, conducted by travel company, should include:

— search for potential consumers;

— study of their needs, of existing and future demand;

- current observation of targeted market;

— forecast of long-term tendencies of market development;

- allocation of methods of the increase of competitiveness of tourist product and company on the whole.

Marketing research should have a complex and systemic character, and scientific approach should be observed during their conduct; they should be well planned and consist of complex of successive actions (stages).

Stages of conduct of marketing research:

1. Allocation of problems and formulation of the purposes of the research;

2. Selection of information sources;

3. Collection of information;

4. Analysis of collected information;

5. Presentation of the received results;

6. Analysis of the research use.

All these stages are interconnected and inseparable.

Allocation of problems and formulation of the purposes of the research. Successful conduct of marketing research requires allocation of the problems of the company and formulation of the goals of the research. The purposes may be:

- Search ones, i.e., suppose collection of preliminary data which sheds light on the problem and, maybe, helps to develop a hypothesis;

- descriptive, i.e., suppose the description of certain phenomena - for example, find the statistics regarding the people that use services of this company;

- experimental, i.e., supposing the verification of hypothesis regarding certain causal relationships;

The next stage of the conduct of marketing research is collection of information source. Primary or secondary data can be gathered. Secondary data is the information that already exists somewhere, having being gathered for other purposes. Primary data is the information that is collected for the first time for specific goal.

Information collection. Methods of marketing research. Usually, research begins with collection of secondary data which is starting point for the research. They are cheaper and more accessible. Depending on the direction and research, information can be gathered from various sources. The research could be divided into intra-company research and research of external environment. The sources of information for intra-company research are, primarily, various 
accounting documents which characterize the work of the company. They are created by company's employees. During the research of external environment, information is usually taken from three main sources: own sources, ordered information, independent sources - reports, reviews, selections, etc., published by various scientific \& research, marketing, and other companies and societies.

Analysis of the gathered information. The next stage of marketing research is extraction from the received information of the most important data and results; this received data is put into tables and processes with the help of statistical methodologies.

Presentation of received results. Researcher should strive for the results of the marketing research, provided by them, to be vivid and with the smallest possible number of uncertainties. These results will give the marketing managers the possibility to make more reasoned decisions.

Analysis of the research use. It is obvious that it is important not only to conduct marketing research - its results are also of great importance. Therefore, it is necessary to compare the tasks of the conducted marketing research and its results. Have the results of the marketing research been used? Have they being used fully? Actually, at this stage, it is possible to find drawbacks and positive moments in the conduct of the research, which can be useful in future during the conduct of other marketing research. According to the results of the conducted research, the tourist company develops marketing strategy.

\section{Conclusions}

Thus, it is obvious that development of tourist industry requires a complex of measures which consists in:

- formation of effective system of financial support;

- development and stimulation of business activities in the sphere of tourism;

- preparation of highly-qualified specialists in the sphere of tourism;

- use of advertising and image policy;

- development of the system of evaluation of quality of offered tourist services (including through the system of classification and obligatory certification);

- expansion and implementation of informational technologies, which will stipulate the most convenient consumption of tourist service: use of technologies of visualization of expected trips; preliminary reservation; full informational support of tourist tour, including transport one.

Implementation of these events of tourism development and use of marketing instrumentarium will result in creation of modern and technically equipped tourist industry that is capable of satisfying the needs of the Russians and foreigners. Complex development of the chosen directions will lead to strengthening of material base of tourism and provision of comfort of accommodation and expansion of diversity of tours. It is necessary to form modern tourist and recreational clusters which correspond to international requirements to infrastructure level, material and technical base, and maintenance service, and provide satisfaction of needs in various tourist services. Modern system of preparation of staff for tourist business and related spheres should be also created.

\section{References}

Arakcheeva, Z.V. (2015). The role of tourism in socio-economic life of the region. SCIENCE TIME, 1, 17-23.

Bokareva, E. V., Egorova E. (2014) The Effect of Tax Preferences on the Formation of a Profitable Part of Budgets Service in Russia and abroad. No. 9 (56). P. 161-170.

Basovskili, L.E. (1999). Marketing: Lectures. M.: INFRA-M, 17.

Dzhandzhugazova, E.A., Pervunina, S.N. (2015). Russian tourism: the anatomy of the crisis. Russian Regions: a look into the future. 1, 116-129.

Durovich, A.P. (2008). Marketing research in tourism - St. Petersburg. Piter, 194.

Istomina, T.S. Samoilenko, A.A. (2015). Travel to Russia - a test of strength. Resorts. Service. Hiking, 1, 27-31.

Egorova E.N.(2013) Taxation as a Tool of Improvement of Competitiveness of Small Enterprises in the Sphere of Tourism World Applied Sciences Journal. T. 24. № 11. C. 1455-1459.

Egorova E. N. (2014) Prospects of Modernization of the Taxation of Small Enterprises in the Sphere of Tourism. Financial Analytics: Problems and Solutions. No. 6. P. 28-33.

Egorova E. N., Lapitskaya N. (2013) In. Strategic Orientations of Modern Tax Policy of Russia. Service in Russia and abroad. No. 9 (47). P. 5-14.

Egorova E. N.(2011) Tax Passport as the Basis of the Information Base of the Tax Potential of the Region. In book: Economics and management: new challenges and perspectives a collection of articles of the II International scientific-practical conference, 
November 7-8, 2011 city hall, Togliatti, Ruse University "Angel Kynev", Bulgaria, Khmelnitsky national. University, Ukraine, Kazakh University of economy, Finance and international Trade, Republic of. Kazakhstan, GKOO Alliance Francaise Togliatti", Tiens Hungary Kft, Budapest, Hungary, Pressevertrie "Schwarz", Germany [etc.]; [PREV. Univ. L. I. Erokhina]. Togliatti, P. 53-55. Karmanova, T.E., Podsevalova, E.N., Zikirova, S.S., Silaeva, A.A., Leonova V.P. (2015) Cluster Model of Regional Tourist Business in Russia. Asian Social Science, T. 11, № 6, 279-286.

Kuftyrëv I.G. (2011). The development of the tourism sector as an industry of Nizhny Novgorod Region market within the regional innovation system, 70.

Silaeva, A.A., Chkhikvadze, N.A. (2010). Marketing as a tool of competitiveness in the tourism market. Problems of practical management and marketing in the field of service Proceedings of the scientific-practical conference, 277-284.

Strategy of tourism development in the Russian Federation for the period up to 2020 . Order of May 31, 2014 №941- $p$.

F. Kotler, John Bowen, J. Meykenz. (1998). Marketing Hospitality Tourism - M.: UNITY, 51.

Chernikova, L.I., Kiselev, A.S. (2013). Effect of intra-marketing on the final result of the enterprise. Service in Russia and abroad. 6, 8396.

Chernikova, L.I. Insurance and risk in tourism (2010). Study manual. M.: Academy. 160.

Shpilev, I.N. (2015). International tourism: theoretical and methodological foundations and development trends. Consumer cooperatives, $1,74-76$. 